\title{
Technical note: Ruminal cannulation technique in young Holstein calves: Effects of cannulation on feed intake, body weight gain, and ruminal development at six weeks of age
}

\author{
N. B. Kristensen, ${ }^{* 1}$ M. Engbæk, ${ }^{*}$ M. Vestergaard, ${ }^{*}$ and D. L. Harmon† \\ *Department of Animal Health and Bioscience, Faculty of Agricultural Sciences, Aarhus University, DK-8830 Tjele, Denmark \\ †Department of Animal and Food Sciences, University of Kentucky, Lexington, KY 40546
}

\begin{abstract}
Ruminal cannulation techniques are frequently used to study fermentation in the ruminant forestomach. Unsatisfactory results with the traditionally applied procedure for cannulation of young calves stimulated the development of a simpler and more robust procedure; this procedure was tested for effects on performance traits and gross anatomy of the gastrointestinal tract compared with a control group not undergoing surgery. Five calves were ruminally cannulated at approximately $10 \mathrm{~d}$ of age and 5 matching calves were used as controls. All calves were fed milk replacer and a diet based on clover grass silage and sodium hydroxide-treated wheat. Ruminal fluid was collected from cannulated calves once weekly for 3 consecutive weeks. All calves were euthanized at $43 \pm 3 \mathrm{~d}$ of age. No apparent adverse effects of cannulation were observed. Feed intake, BW gain, and gross anatomy of the gastrointestinal tract were not affected by cannulation. Minimum ruminal $\mathrm{pH}$ increased with sampling week, but average ruminal $\mathrm{pH}$, total volatile fatty acids concentration, and volatile fatty acids proportions were not affected by sampling week. In conclusion, the implemented surgical technique was found to have no major effect on apparent animal health and performance traits, and the cannula proved useful for multiple samplings of ruminal contents in young calves.
\end{abstract}

Key words: ruminal cannula, ruminal environment, calf

We have done intensive research trials over the past 5 yr to study the effects of various feeding strategies on the ruminal environment and ruminal development in young Holstein calves (e.g., Kristensen et al., 2007). For these studies, 40 milk-fed calves (most calves had surgery at the age of $7 \mathrm{~d}$ ) were ruminally cannulated

Received June 15, 2009.

Accepted October 30, 2009

${ }^{1}$ Corresponding author: nbk@agrsci.dk according to the stab-wound procedure originally described by Phillipson and Innes (1939). None of the calves developed peritonitis and all calves healed quickly with a complete adhesion around the fistula. However, it proved difficult for the young calves to absorb the sutures placed at the left paracostal laparatomy incision ventral to the fistula. Various synthetic absorptive sutures, plain catgut, and steel were tried in order to find material that either would be effectively absorbed by the calves or remain in the tissue without causing a wound infection later. It was also attempted to minimize infections by flushing the wound during closure with saline containing benzyl penicillium, but none of the attempts proved satisfactorily. Despite good growth rates and a low incidence of disease in these trials, several of the calves developed a visible and palpable abscess in the area of the incision ventral to the fistula.

At least 3 different ruminal fistulation techniques have been used in cattle: 1) the stab-wound technique (Phillipson and Innes, 1939), 2) the pouch technique (Dougherty, 1955), originally using clamps to hold the rumen tissue (Schalk and Amadon, 1928), and 3) the one-stage technique (Noordsy and Trotter, 1963), originally used in treatment of bloat. The stab-wound technique is commonly used to establish permanent cannulas that can be removed only with invasive procedures. The 2 other methods have been used to establish larger fistulas that are closed using commercially available cannulas (e.g., Hentschl et al., 1954). The aim of the present work was to combine the advantages of the small, permanent cannula and the one-stage fistulation technique, employing a single incision so as to not leave sutures in the tissues after the healing of the fistula.

Because our work deals with ruminal development, it was of concern how the calf was affected by the ruminal cannula that was implanted at a very early stage of ruminal development, even though the wound was healing as intended. We have not been able to find data pertaining to these concerns as related to the very young calf. However, these concerns increase in calves where the wound becomes infected. 
A
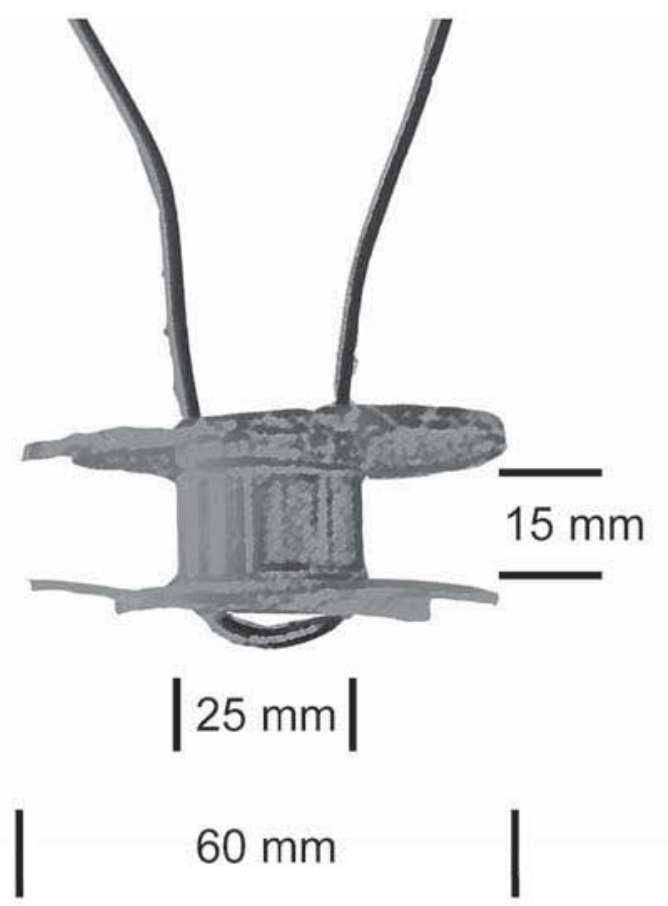

B

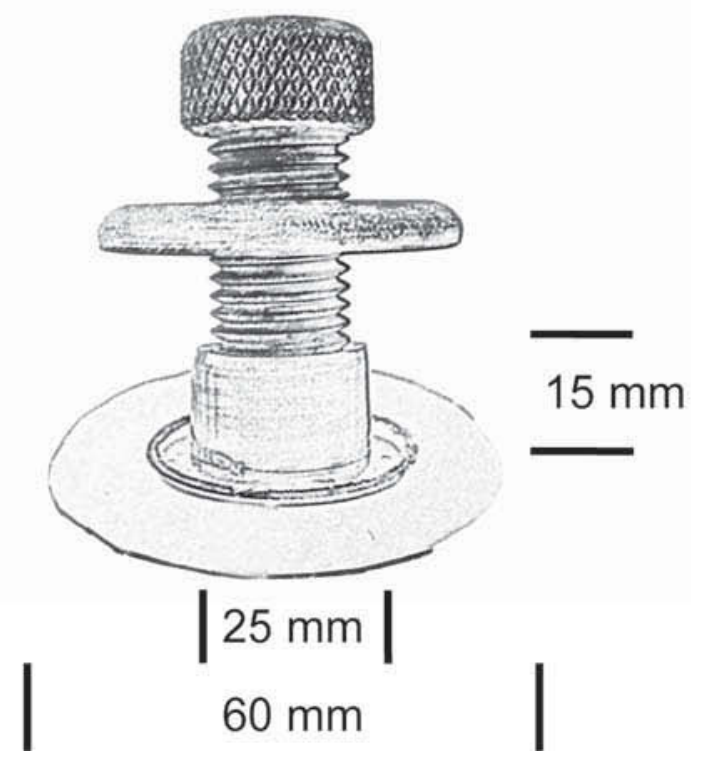

Figure 1. A) Temporary cannula and B) permanent cannula. Flanges of the temporary cannula and the large inner flange of the permanent cannula were made of soft polyvinyl chloride (PVC). The permanent cannula was made of hard PVC (20 mm o.d., $14 \mathrm{~mm}$ i.d.). The inner flange was made of hard PVC (35 mm o.d.) inside a soft PVC flange $(60 \mathrm{~mm}$ o.d.). The bottom $15-\mathrm{mm}$ thread of the cannula cylinder was covered by a piece of silicone tubing to protect the fistula and the final diameter of the permanent cannula was similar to the diameter of the temporary cannula. The adjustable outer flange of hard PVC had an outside diameter of $50 \mathrm{~mm}$ (Hammersh $\varnothing \mathrm{j}$ Maskinteknik, Hammersh $\varnothing \mathrm{j}$, Denmark). The temporary cannula was easy to remove after the healing of the wound by cutting the wires and was replaced by the permanent cannula after cleaning and inspection of the wound.
Therefore, the objectives of the present study were to establish an alternative surgical technique for ruminal cannulation of 1 - to 2 -wk-old calves and to evaluate the ruminal environment, ruminal development, and performance of cannulated calves as compared with a control group that had not underwent surgery.

The present experiment complied with the Danish Ministry of Justice Law no. 382 (June 10, 1987), act no. 726 (September 9, 1993) concerning experiments with animals and care of experimental animals. Ten Danish Holstein calves (6 males and 4 females; 8 single delivery, 2 female twins) delivered by second-parity cows were allocated to 5 blocks according to gender, birth weight, and date of birth and were allocated randomly to either the control treatment (no surgery) or cannulation. Calves underwent surgery at an age of $10 \pm 3 \mathrm{~d}$. The day before cannulation, solid feed was withdrawn in the afternoon and calves were not fed milk on the morning of surgery. The calves were anesthetized by intramuscular injection of Xylazine $(0.15 \mathrm{mg} / \mathrm{kg}$ of BW) followed by intravenous injection of Ketamine $(3 \mathrm{mg} /$ $\mathrm{kg}$ of BW) and immediately intubated. Anesthesia was maintained with isoflurane in oxygen using mechanical ventilation.

The surgical procedure was based on the one-stage procedure developed for adult ruminants (T. B. Avery, Kansas State University, Manhattan, personal communication; Noordsy and Trotter, 1963). Calves were shaved, scrubbed, and general aseptic surgical procedures were applied. A circular 25-mm skin incision was placed in the center of the left paralumbar fossa. The muscle layers were separated by blunt dissection and the peritoneum incised using scissors. The rumen was fixed with Allis forceps, taking care to fix it at the left lateral face of the wall. The rumen wall was sutured to the skin using 4 interrupted mattress sutures (Polysorb U.S.P. size 2-0 mounted on a $24-\mathrm{mm}$ cutting needle; United States Surgical, Tyco Healthcare Group LP, Norwalk, CT) placed at 12, 3, 6, and 9 o'clock. The rumen was opened using a scalpel and the corners rounded using scissors, and a simple continuous suture (Polysorb U.S.P. size 2-0) was used to suture the rumen to the skin around the entire incision. Care was taken to exteriorize the rumen wall and fold it over the skin around the entire incision. This aids in directing any leakage of rumen contents to the exterior.

A hard polyvinyl chloride (PVC) disc (15 mm height $\times 25 \mathrm{~mm}$ o.d.) was inserted in the fistula and fixed with soft PVC inner and outer flanges of approximately 60 $\mathrm{mm}$ in diameter (Figure 1A). This device was left undisturbed for at least $10 \mathrm{~d}$ post-surgery. Both treatment groups were treated with nonsteroidal antiinflammatory drugs and antibiotics for 3 and 5 d after surgery, respectively. 
After healing, on d 10 post-surgery, the temporary device was removed along with the ring of rejected tissue containing the sutures, and the wound was cleaned. A cannula of hard PVC (70 mm length, $20 \mathrm{~mm}$ o.d., $14 \mathrm{~mm}$ i.d.) was inserted. The inner flange was of hard PVC (35 mm o.d.) inside a soft PVC flange $(60 \mathrm{~mm}$ o.d.; Figure 1B). The bottom 15-mm thread of the cannula cylinder was covered by a piece of silicone tubing to protect the fistula, resulting in a cannula with the same outside diameter as the temporary cannula. The adjustable outer flange of hard PVC had an outside diameter of $50 \mathrm{~mm}$ (Hammershøj Maskinteknik, Hammershøj, Denmark).

Calves were kept in individual pens $(1.20 \mathrm{~m} \times 2.50$ $\mathrm{m})$ with partitions that allowed contact between the calves. The milk feeding regimen was $4.84 \mathrm{~kg}$ of milk replacer (123 g of DM/kg of milk replacer; Friska Sød DLG, Copenhagen, Denmark; Kristensen et al., 2007) divided into 2 equally sized portions that were fed at 0800 and $1400 \mathrm{~h}$. Milk replacer was fed in nipple buckets.

Calves had ad libitum access to a solid feed mixture (Table 1) in a wall-mounted bucket. Orts were removed and weighed daily. Each pen had an individual bowl drinker with open water surface and a rubber mat, and wood shavings were used as bedding. Bedding was replaced twice daily. Calves were weighed at birth, at d 4 , and 2 times per week thereafter. Final weight was obtained immediately before harvest.

Ruminally cannulated calves were sampled 3 times at weekly intervals. At each sampling, a total of 6 ruminal fluid samples $(20 \mathrm{~mL})$ were obtained from the ventral ruminal sac using a suction strainer (Bar Diamond, Parma, ID) every $2 \mathrm{~h}$ from 0700 to $1700 \mathrm{~h}$. Ruminal fluid $\mathrm{pH}$ was measured immediately after sampling each calf using a combination electrode (PHC2002-8, Hach Lange APS, Brønsh $\varnothing$ j, Denmark) and a pH meter calibrated at $\mathrm{pH} 4.005$ and 7.000 (PHM 240, Hach Lange APS). Immediately after reading $\mathrm{pH}$, a subsample of ruminal fluid was stabilized with a final concentration of $5 \%$ metaphosphoric acid and frozen at $-20^{\circ} \mathrm{C}$.

The calves were killed by captive bolt stunning and exsanguination. The gastrointestinal tract, liver, and kidneys were harvested immediately and viscera-free carcass weight was determined (including head, hide, feet, and tail). Regions of the gastrointestinal tract were isolated by tying with string and dissected into reticulorumen, omasum, and abomasum. The kidneys were dissected into organ and perirenal fat. Total weights and weights of contents and empty organs were measured and recorded. The reticulorumen was rinsed in tap water and examined for papillary aggregation, edema, and necrosis in the atrium and cranial part of the ventral ruminal sac. A ruler was used to measure
Table 1. Composition of the solid feed mixture

\begin{tabular}{|c|c|}
\hline Item, g/kg DM & Value \\
\hline Clover grass silage $^{1}$ & 258 \\
\hline Sodium hydroxide-treated whole wheat ${ }^{2}$ & 565 \\
\hline Xylose-treated soybean meal ${ }^{3}$ & 92 \\
\hline Corn gluten $60 \%$ & 50 \\
\hline Mineral and vitamin premix ${ }^{4}$ & 10 \\
\hline Palm fatty acid distillate & 10 \\
\hline $\mathrm{CaCO}_{3}$ & 7.5 \\
\hline $\mathrm{NaCl}$ & 7.5 \\
\hline $\mathrm{Mg}_{3}\left(\mathrm{PO}_{4}\right)_{2}$ & 5.0 \\
\hline $\mathrm{Na}_{2}\left(\mathrm{SO}_{4}\right)$ & 1.5 \\
\hline Vitamin E premix ${ }^{5}$ & 1.0 \\
\hline $\mathrm{Cr}_{2} \mathrm{O}_{3}$ (marker) & 1.0 \\
\hline
\end{tabular}

${ }^{1}$ Eurofins Steins Laboratorium A/S, Holstebro, Denmark. Composition: $41.7 \%$ DM; $16.6 \% \mathrm{CP} ; 8.6 \%$ ash; $83.4 \%$ in vitro digestibility of OM.

${ }^{2}$ Wheat treated with $3 \%$ sodium hydroxide.

${ }^{3}$ Soy Pass, Vestjyllands Andel, Ringkøbing, Denmark.

${ }^{4}$ VM 1, Vitfoss, Gråsten, Denmark. Contained (per kg): $145 \mathrm{~g}$ of Ca, 4 $\mathrm{g}$ of $\mathrm{P}, 85 \mathrm{~g}$ of $\mathrm{Mg}, 100 \mathrm{~g}$ of $\mathrm{Na}, 40 \mathrm{~g}$ of S, $900 \mathrm{kIU}$ of vitamin A, 190 $\mathrm{kIU}$ of vitamin $\mathrm{D}_{3}, 6,000 \mathrm{mg}$ of $\alpha$-tocopherol, 4,000 $\mathrm{mg}$ of $\mathrm{Mn}, 1,500$ $\mathrm{mg}$ of $\mathrm{Cu}, 25 \mathrm{mg}$ of $\mathrm{Co}, 4,500 \mathrm{mg}$ of $\mathrm{Zn}, 225 \mathrm{mg}$ of I, and $50 \mathrm{mg}$ of Se.

${ }^{5}$ Suplex d-alfa E 50000, Vitfoss, Gråsten, Denmark. Contained 33,557 $\mathrm{mg}$ of $\mathrm{D}-\alpha$-tocopherol $/ \mathrm{kg}$.

the length of randomly selected papillae at ventral and medial positions of the atrium and ventral and medial positions of the ventral ruminal sac.

Ruminal fluid was analyzed for glucose (glucose oxidase) and L-lactate (L-lactate oxidase; YSI 7100 analyzer, YSI Inc., Yellow Springs, OH). Ruminal fluid VFA were analyzed by gas chromatography (Kristensen et al., 1996). Feed samples were dried at $60^{\circ} \mathrm{C}$ for $48 \mathrm{~h}$ in a forced-air oven.

Weight, age, and feed intake data obtained for all 10 calves at the 3 sampling weeks were considered as repeated measures (weeks) and analyzed using the autoregressive order 1 structure in the MIXED procedure of SAS (version 9.1, SAS Institute Inc., Cary, NC). The model included the fixed effects of treatment, weeks, and treatment $\times$ weeks.

Ruminal variables with 6 samplings within sampling day were considered as repeated measures (time) and analyzed using the autoregressive order 1 , heterogeneous autoregressive order 1, or factor analytic (1) covariance structures based on fit statistics and ability to solve the model using the MIXED procedure of SAS. The model included the fixed effects of weeks and time, and the interaction between weeks and time. Calf $\times$ week was designated as a random effect. Data with 1 observation per calf (birth weight, final weight, and harvest data) were analyzed using the MIXED procedure of SAS with a model containing the fixed effect of treatment. All values were given as least squares means \pm standard error. Significance was declared at $P<0.05$. 
Table 2. Age, BW, feed intake, gain, and ruminal variables of calves at the 3 samplings

Week 2

Week 3

$P$-value

Item

Week 1

Age at sampling, d

BW at sampling, $\mathrm{kg}$

Intake milk DM, g/d

Intake feed mix DM, g/d

$\mathrm{BW}$ gain, $\mathrm{g} / \mathrm{d}$

Ruminal $\mathrm{pH}$

Minimum ruminal $\mathrm{pH}$

Duration of ruminal $\mathrm{pH}<5.5, \mathrm{~h} / \mathrm{d}$

Duration of ruminal $\mathrm{pH}<5.8, \mathrm{~h} / \mathrm{d}$

Duration of ruminal $\mathrm{pH}<6.2, \mathrm{~h} / \mathrm{c}$

Total VFA, mmol/L

Propionate, $\mathrm{mol} / 100 \mathrm{~mol}$

Isobutyrate, $\mathrm{mol} / 100 \mathrm{~mol}$

Butyrate, mol/100 mol

Isovalerate, $\mathrm{mol} / 100 \mathrm{~mol}$

Valerate, $\mathrm{mol} / 100 \mathrm{~mol}$

Caproate, mol/100 mol

Glucose, mmol/L

\begin{tabular}{cc} 
Control & Cannulated \\
\hline 26 & 25 \\
51 & 48 \\
595 & 595 \\
265 & 327 \\
642 & 646 \\
- & 6.12 \\
- & 5.82 \\
- & 0 \\
- & 4 \\
- & 16 \\
- & 102 \\
& 51 \\
& 31 \\
& 0.7 \\
& 13 \\
& 0.7 \\
& 4.0 \\
& 0.5 \\
& 0.21 \\
& 0.9
\end{tabular}

\begin{tabular}{cc}
\multicolumn{2}{c}{ Week 2} \\
\hline & \\
Control & Cannulated \\
\hline 33 & 32 \\
56 & 53 \\
595 & 595 \\
522 & 580 \\
702 & 806 \\
- & 6.23 \\
- & 5.97 \\
- & 0 \\
- & 3 \\
- & 8 \\
& 105 \\
& 57 \\
& 22 \\
& 0.7 \\
& 15 \\
& 0.7 \\
& 3.5 \\
& 0.7 \\
& 0.25 \\
& 2.0
\end{tabular}

\begin{tabular}{r}
\hline \\
\hline Contr \\
\hline 39 \\
62 \\
595 \\
792 \\
879 \\
- \\
- \\
- \\
- \\
-
\end{tabular}

(n)

L-Lactate, $\mathrm{mmol} / \mathrm{L}$

${ }^{1}$ Treatments: 5 calves were ruminally cannulated at approximatel

based on clover grass silage and sodium hydroxide-treated wheat. Performance traits and ruminal variables (cannulated calves) were recorded for 3 consecutive weeks. 
Table 3. Slaughter data obtained from control and ruminally cannulated calves

\begin{tabular}{lcccc}
\hline & \multicolumn{2}{c}{ Treatment $^{1}$} & & \\
\cline { 2 - 3 } Item & Control & Cannulated & SEM & P-value \\
\hline Birth weight, kg & 38 & 36 & 4 & 0.81 \\
Final weight, kg & 67 & 64 & 3 & 0.51 \\
Age at harvest, $\mathrm{d}$ & 43 & 42 & 3 & 0.91 \\
Visceral free carcass weight, \% of BW & 75 & 75 & 1 & 0.91 \\
Rumen and reticulum, \% of BW & 1.3 & 1.2 & 0.1 & 0.49 \\
Omasum, \% of BW & 0.27 & 0.26 & 0.02 & 0.92 \\
Abomasum, \% of BW & 0.56 & 0.56 & 0.02 & 0.86 \\
Liver, \% of BW & 1.9 & 2.0 & 0.1 & 0.31 \\
Kidneys, \% of BW & 0.45 & 0.43 & 0.02 & 0.54 \\
Perirenal fat, \% of BW & 0.21 & 0.20 & 0.02 & 0.73 \\
Digesta in rumen and reticulum, \% of BW & 6.1 & 6.3 & 0.5 & 0.75 \\
Papillae in ventral atrium, mm & 4.9 & 4.2 & 0.5 & 0.35 \\
Papillae in lateral atrium, mm & 3.4 & 2.4 & 0.5 & 0.23 \\
Papillae in ventral ventral sac, mm & 1.1 & 0.7 & 0.2 & 0.24 \\
Papillae in lateral ventral sac, mm & 2.5 & 1.8 & 0.5 & 0.31 \\
\hline
\end{tabular}

${ }^{1}$ Five calves were ruminally cannulated at approximately $10 \mathrm{~d}$ of age (treatment), and 5 matching calves were used as controls. All calves were fed milk replacer and a mixed ration based on clover grass silage and sodium hydroxide-treated wheat.

No adverse effects of ruminal cannulation were observed for any of the calves, and apparent drinking, eating, rumination, resting, and alertness was similar for the 2 treatment groups. None of the cannulated calves developed abscesses as previously observed with the stab-wound technique. In 1 of the 5 cannulated calves the subiliaci lymph node (located halfway between tuber coxae and patella) was palpable before slaughter, but no abscess formation was observed. Complete healing of the fistulas was observed for all calves when the temporary cannula was replaced at least $10 \mathrm{~d}$ after surgery. No infections were apparent after replacing cannulas, and in all calves the rejected ring of tissue containing the sutures was fully separated and could be removed with the temporary cannula, confirming complete fistula formation. We consider the rejection of the tissue containing the sutures to be the determining factor in the success of the presented technique as compared with the previously used technique in young calves because, with the rejection, no foreign material remains in the wound after healing.

Cannulation did not affect $(P=0.52$ to $P>0.99)$ intake of milk DM, intake of solid feed mixture DM, or BW gain of the calves (Table 2). Overall, BW gain and voluntary intake of solid feed were at least at a level comparable with earlier studies on calves at similar ages (Coverdale et al., 2004; Lesmeister and Heinrichs, 2004; Kristensen et al., 2007).

The solid feed mixture used in the present experiment is not commonly fed to young calves; however, previous experiments have demonstrated SARA in young calves fed conventional grain-based commodity starter diets (Anderson et al., 1987; Lesmeister and Heinrichs, 2004;
Kristensen et al., 2007), and we aimed to test sampling from the implanted cannula when feeding young calves a TMR as an alternative to a traditional starter supplemented with hay. The minimum ruminal $\mathrm{pH}$ increased $(P=0.03)$ with sampling week and duration of $\mathrm{pH}<6.2$ tended $(P=0.08)$ to decrease with week, and both variables indicated improved ruminal environment as the calves matured and improved ruminal environment compared with the studies listed above. The possibility of an effect of the cannulation technique upon the rumen environment and the measured variables cannot be rejected, but we do not expect that the improved cannulation technique would explain the improved environment compared with the previous studies. In agreement with the $\mathrm{pH}$ variables, all VFA variables were indicative of an improved ruminal environment (i.e., lower molar proportion of propionate compared with trials based on commodity starters; Lesmeister and Heinrichs, 2004; Kristensen et al., 2007).

None of the slaughter data indicated that ruminal cannulation affected gross anatomy of the gastrointestinal tract (Table 3). All relative organs and digesta contents were within the range previously observed in calves fed commodity starter (Kristensen et al., 2007) except that the mass of digesta in the reticulorumen was larger in the present study (6.2 versus $3.6 \%$ in the previous study), properly reflecting greater roughage intake with the TMR used in the present study.

It is concluded that the ruminal cannulation method implemented and tested in the present study is preferable compared with the stab-wound method previously used in young calves and that the cannulation procedure did not have detectable effect on feed intake, 
performance traits, and gross anatomy of the gastrointestinal tract of young calves.

\section{REFERENCES}

Anderson, K. L., T. G. Nagaraja, and J. L. Morrill. 1987. Ruminal metabolic development in calves weaned conventionally or early. J. Dairy Sci. 70:1000-1005.

Coverdale, J. A., H. D. Tyler, J. D. Quigley III, and J. A. Brumm. 2004. Effect of various levels of forage and form of diet on rumen development and growth in calves. J. Dairy Sci. 87:2554-2562.

Dougherty, R. W. 1955. Permanent stomach and intestinal fistulas in ruminants: Some modifications and simplifications. Cornell Vet. 45:331-357.

Hentschl, A. F., R. N. Berry, and C. F. Huffman. 1954. A plastic plug for use in the bovine fistula. M.S.C. Vet. 14:77-81.
Kristensen, N. B., A. Danfær, V. Tetens, and N. Agergaard. 1996. Portal recovery of intraruminally infused short-chain fatty acids in sheep. Acta Agric. Scand. Sect. A 46:26-38.

Kristensen, N. B., J. Sehested, S. K. Jensen, and M. Vestergaard. 2007. Effect of milk allowance on concentrate intake, ruminal environment, and ruminal development in milk-fed Holstein calves. J. Dairy Sci. 90:4346-4355.

Lesmeister, K. E., and A. J. Heinrichs. 2004. Effects of corn processing on growth characteristics, rumen development, and rumen parameters in neonatal dairy calves. J. Dairy Sci. 87:3439-3450.

Noordsy, J. L., and D. M. Trotter. 1963. A modified rumen fistula technique for chronic tympanitis. Vet. Med. 58:498-501.

Phillipson, A. T., and J. R. M. Innes. 1939. Permanent stomach fistulæ in ruminants. Q. J. Exp. Physiol. 29:333-341.

Schalk, A. F., and R. S. Amadon. 1928. Physiology of the ruminant stomach (bovine). Study of the dynamic factor. N. Dakota Agric. Sta. Bul. 216. Agricultural Experiment Station, North Dakota Agricultural College, Fargo. 